\title{
Extracellular Matrix Plasticity and GABAergic Inhibition of Prefrontal Cortex Pyramidal Cells Facilitates Relapse to Heroin Seeking
}

\author{
Michel C Van den Oever*,', Bart R Lubbers', Natalia A Goriounova², Ka W Li', Roel C Van der Schors', \\ Maarten Loos', Danai Riga', Joost Wiskerke', Rob Binnekade ${ }^{3}$, M Stegeman $^{3}$, Anton NM Schoffelmeer ${ }^{3}$, \\ Huibert D Mansvelder', August B Smit', Taco J De Vries ${ }^{1,3,4}$ and Sabine Spijker ${ }^{1,4}$ \\ 'Department of Molecular and Cellular Neurobiology, Center for Neurogenomics \& Cognitive Research, VU University Amsterdam, Amsterdam, \\ The Netherlands; '2Department of Integrative Neurophysiology, Center for Neurogenomics \& Cognitive Research, VU University Amsterdam, \\ Amsterdam, The Netherlands; ${ }^{3}$ Department of Anatomy and Neurosciences, VU Medical Center, Amsterdam, The Netherlands
}

Successful treatment of drug addiction is hampered by high relapse rates during periods of abstinence. Neuroadaptation in the medial prefrontal cortex (mPFC) is thought to have a crucial role in vulnerability to relapse to drug seeking, but the molecular and cellular mechanisms remain largely unknown. To identify protein changes that contribute to relapse susceptibility, we investigated synaptic membrane fractions from the mPFC of rats that underwent 21 days of forced abstinence following heroin self-administration. Quantitative proteomics revealed that long-term abstinence from heroin self-administration was associated with reduced levels of extracellular matrix (ECM) proteins. After extinction of heroin self-administration, downregulation of ECM proteins was also present in the mPFC, as well as nucleus accumbens (NAc), and these adaptations were partially restored following cue-induced reinstatement of heroin seeking. In the mPFC, these ECM proteins are condensed in the perineuronal nets that exclusively surround GABAergic interneurons, indicating that ECM adaptation might alter the activity of GABAergic interneurons. In support of this, we observed an increase in the inhibitory GABAergic synaptic inputs received by the mPFC pyramidal cells after the re-exposure to heroin-conditioned cues. Recovering levels of ECM constituents by metalloproteinase inhibitor treatment (FN-439; i.c.v.) prior to a reinstatement test attenuated subsequent heroin seeking, suggesting that the reduced synaptic ECM levels during heroin abstinence enhanced sensitivity to respond to heroin-conditioned cues. We provide evidence for a novel neuroadaptive mechanism, in which heroin self-administrationinduced adaptation of the ECM increased relapse vulnerability, potentially by augmenting the responsivity of mPFC GABAergic interneurons to heroin-associated stimuli.

Neuropsychopharmacology (2010) 35, 2120-2।33; do:I0.1038/npp.2010.90; published online 30 June 2010

Keywords: addiction; reinstatement; mPFC; proteomics; synaptic plasticity; cognition and behavior

\section{INTRODUCTION}

Treatment of drug addiction is hindered by a high incidence of relapse to drug taking during periods of drug abstinence. During drug intake, environmental stimuli become associated with the drugs' rewarding effects (O'Brien et al, 1986). Exposure to these drug-conditioned cues can provoke drug craving and subsequent relapse to drug use even after

* Correspondence: DrMC Van den Oever, Department of Molecular and Cellular Neurobiology, Center for Neurogenomics \& Cognitive Research, Neuroscience Campus Amsterdam, Vrije Universiteit, De Boelelaan I085, Amsterdam 108I HV, The Netherlands, Tel: + 3 I 20598 7I20, Fax: + 3120 598928I, E-mail: michel.van.den.oever@cncr.vu.nl

${ }^{4}$ These authors contributed equally to this work.

Received 24 February 2010; revised II May 20I0; accepted 28 May 2010 prolonged periods of abstinence (Wikler, 1973; O’Brien et al, 1986). During the last decade, it has become clear that exposure to drugs of abuse leads to long-lasting changes in neuronal circuitry that mediates processing of motivationally relevant stimuli (Robinson and Berridge, 1993; Kalivas and Volkow, 2005). However, the molecular mechanisms underlying these changes, as well as how they contribute to relapse to drug seeking remain largely unresolved.

With respect to opiate drugs, heroin administration leads to long-term alterations in gene expression in the NAc shell (Jacobs et al, 2002). At the cellular level, changes in neuronal connectivity and neuronal physiology have been observed after opiate exposure. For instance, morphine treatment leads to changes in the complexity of dendritic branching on cells in the neocortex and hippocampus during development (Hammer et al, 1989) and affects the number of synaptic 
spines and dendritic arborizations of the neurons in the mPFC and NAc (Robinson and Kolb, 1999; Robinson et al, 2002). In addition to structural changes, opiate exposure also results in a change in synapse physiology of neurons in the ventral-tegmental area (Saal et al, 2003), hippocampus ( $\mathrm{Pu}$ et al, 2002), and NAc (Dong et al, 2007), and leads to long-lasting changes in dopamine and acetylcholine release at nerve terminals in the striatum (Tjon Tien Ril et al, 1993; Tjon et al, 1994; Vanderschuren et al, 2001). Recently, we found that re-exposure to heroin-conditioned cues results in acute synaptic depression of pyramidal neurons in the ventral mPFC (Van den Oever et al, 2008). Thus, addiction might be a pathological process that involves mechanisms of synaptic plasticity similar to those observed in neuronal models of learning and memory (Nestler, 2002; Kelley, 2004; Hyman, 2005), arguing for a thorough analysis of long-lasting changes in synaptic function resulting from drug exposure.

The $\mathrm{mPFC}$ is a brain area that has a pivotal role in relapse to opiate seeking during periods of drug abstinence (Schmidt et al, 2005; Koya et al, 2006; Rogers et al, 2008; Van den Oever et al, 2008). Drug-induced neuroadaptations in the mPFC might be intrinsic to the synapse, eg glutamate receptor-based plasticity, or extrinsic, eg by changing the extracellular matrix (ECM). In the last decade, the role of the ECM and more specifically the role of matrix molecules in perineuronal nets, both in neural development and synaptic plasticity, has attracted attention (Pizzorusso et al, 2002; Dityatev and Schachner, 2003). Studies on the role of the ECM in plasticity of the visual cortex (Pizzorusso et al, 2002, 2006) and hippocampal-dependent learning (Meighan et al, 2006) gave way to the intriguing prospect that the ECM contributes to various forms of persistent neuroadaptation (Wright and Harding, 2009), including those resulting from repeated drug exposure. In support of this, a study by Brown et al (2007) suggests that alteration of ECM plasticity by inhibition of matrix metalloproteinase (MMP) activity reduces the conditioned rewarding effects of cocaine in a conditioned place preference model.

In this study, we used a rat model of relapse to heroin seeking (Epstein et al, 2006), in which animals selfadminister heroin in the presence of compound cues (Van den Oever et al, 2008). We show that heroin selfadministration leads to long-term changes in synaptic levels of ECM constituents in the MPFC. Interference of the ECM by a broad-spectrum metalloproteinase inhibitor FN-439 treatment reduced subsequent cue-induced reinstatement of heroin seeking, suggesting that adaptation of the ECM contributes to relapse susceptibility. Moreover, we show that these ECM proteins are condensed in perineuronal nets surrounding mPFC GABAergic interneurons and that cueinduced relapse is accompanied by an increase in spontaneous inhibitory network activity. Together, these data may point toward ECM-mediated enhancement of GABAergic interneuron reactivity to heroin-associated stimuli.

\section{MATERIALS AND METHODS}

\section{Animals}

Male Wistar rats (Harlan, Horst, The Netherlands) weighing 280-300 $\mathrm{g}$ on the day of arrival were single-housed on a reversed 12-h light-dark cycle with standard food (Teklad, Harlan) and water available ad libitum. All experiments were approved by the Animal Users Care Committee of the VU University.

\section{Heroin Self-Administration, Extinction, and Reinstatement}

Animals. Rats that self-administered heroin and controls that self-administered saline were implanted with jugular vein catheters and allowed to recover from surgery for at least 1 week (Schmidt et al, 2005).

Self-administration phase. Rats were trained to selfadminister heroin $(100 \mu \mathrm{g} / \mathrm{kg}$, diacetylmorphine-HCL, OPG, Utrecht, The Netherlands) in operant cages (Med Associates, St Albans, VT, USA) in once daily sessions ( $3 \mathrm{~h}$ ) during the lights-off period for a total of 16 sessions (Schmidt et al, 2005). Nose poking in the active (heroinpaired) hole resulted in a 2-s heroin infusion and the presentation of compound audio-visual cues. For details see Supplementary Methods.

Forced abstinence. After the final self-administration session, rats were left undisturbed in their home cages for 21 days. On the 21 st day of heroin abstinence, rats were decapitated and brains were rapidly frozen using ice-cold $\left(-50^{\circ} \mathrm{C}\right)$ isopentane and stored at $-80^{\circ} \mathrm{C}$ until further use.

Extinction. Additional groups of animals underwent extinction sessions for 60 min once daily for 5 days a week (15 sessions) following heroin self-administration. During the extinction period, heroin was not available and cues were not presented. Extinction was considered successful when nose poking was less than ten nose pokes per session (extinction criterion), as was usually obtained after 10-11 sessions.

Reinstatement. Extinction-trained rats were placed in the operant cages with the discriminative cues turned on and nose poking resulting in the presentation of discrete audiovisual cues (but no heroin infusion) on an FR4 schedule. Control animals underwent an additional extinction session. For electrophysiological recordings and the FN-439 experiment, recording of nose-poke responses in the active and inactive hole was measured until $30 \mathrm{~min}$ after start of the test. For immunoblotting, rats of both cue and no-cue groups were decapitated immediately after the reinstatement/ extinction session, and brains were frozen and stored until further use.

\section{Tissue Preparation, iTRAQ Labeling, and 2D LC-MS/MS}

The mPFC, Nac, and dorsal striatum were dissected freehand at $-20^{\circ} \mathrm{C}$ from $1-\mathrm{mm}$-thick brain slices. Bregma coordinates were inferred from the Paxinos and Watson rat brain atlas: $\mathrm{mPFC}(3.7-2.7 \mathrm{~mm})$ and NAc $(2.1-1.1 \mathrm{~mm})$. Subsequently, the brain tissue of three animals was pooled, resulting in two independent pools per treatment (Supplementary Figure S1). 
Synaptic membrane preparation. The four samples were processed simultaneously and synaptic membranes were isolated as described previously (Van den Oever et al, 2008) (Supplementary Methods).

Protein digestion and TTRAQ labeling. Trypsin digestion of synaptic membrane proteins and iTRAQ labeling of peptides were performed as described in the iTRAQ reagent kit manual (Applied Biosystems, Foster City, CA; Supplementary Methods).

Two-dimensional liquid chromatography (2DLC). The dried iTRAQ sample was separated on a polysulfoethyl A column (PolyLC), and subsequently on a C-18 trap column and an analytical capillary $\mathrm{C}-18$ column. The eluent was mixed with MALDI matrix, delivered at a flow rate of $1.5 \mu \mathrm{l} /$ min and robotically deposited offline to the Applied Biosystems metal target every $15 \mathrm{~s}$ for a total of 192 spots (Supplementary Methods).

Mass spectrometry (MS/MS). MALDI plates were analyzed on a 4700 proteomics analyzer (Applied Biosystems). Peptide CID was performed at $1 \mathrm{kV}$ with nitrogen collision gas. MS/MS spectra were collected from 5000 laser shots. Peptides with signal-to-noise ratio above 50 at the MS mode were selected for MS/MS, at a maximum of $30 \mathrm{MS} / \mathrm{MS}$ per spot. The precursor mass window was set at a relative resolution of 180 (FWHM).

\section{MS Data Analysis And Statistics}

Protein identification. MS/MS spectra were searched against the rat database (Swissprot and NCBI) using GPS Explorer (Applied Biosystems) and Mascot (Matrix Science). Next, a library was generated containing all annotated peptides with a confidence interval $(\mathrm{CI})>20 \%$. Database redundancy and sequence redundancy were removed. Hence, quantification was performed only on those peptides that were annotated to a single protein, and are referred to as 'unique peptides'. Only proteins with $\geqslant 3$ peptides, of which at least one peptide had a CI $\geqslant 95 \%$, were selected for quantification and statistical analysis. Gene Ontology (GO) protein functional classification was performed with the Gene Ontology Tree Machine (GOTM, http://bioinfo.vanderbilt.edu/gotm/).

Protein quantification. iTRAQ areas (m/z 114-117) were extracted from raw spectra and corrected for isotopic overlap using GPS explorer. To compensate for the possible variations in the starting amounts of the samples, the individual peak areas of each iTRAQ signature peak were $\log _{2}$ transformed to obtain a normal distribution and then normalized to the mean peak area for each sample. Significant protein regulation was determined by comparing the average iTRAQ area of labels 114 and 116 (saline groups) with the average iTRAQ area of labels 115 and 117 (heroin groups) of all unique peptides that were annotated to a protein ( $\log _{2}$ scale; Student's $t$-test $p<0.05)$. In addition, the standard deviation $(\sigma)$ was calculated from the heroin-to-saline ratios of all quantified proteins. Proteins with a regulation more than the average regulation $\pm \sigma$ were considered relevant for further validation by immunoblotting.

\section{Immunoblotting}

For immunoblotting, mPFC, NAc, dorsal striatum synaptic membrane fractions, and total protein were isolated from additional groups of animals that self-administered heroin or saline $(n=9$ pool of three, abstinence and extinction experiments) as described above. For the FN-439 experiment, synaptosomal fractions were isolated from individual animals $(n=6$, no pooling). Protein pellets were subsequently treated with chondroitinase ABC (Sigma Aldrich, Zijndrecht, The Netherlands) at $0.5 \mathrm{U} / 50 \mu \mathrm{g}$ protein for $90 \mathrm{~min}$ at $37^{\circ} \mathrm{C}$. SDS-PAGE and immunoblotting were performed according to standard protocols (for details: Supplementary Methods) using the following primary antibodies: mouse anti-Tenascin-R (1:2000; Dr P Pesheva, Bonn, Germany) and rabbit anti-brevican or guinea pig anti-brevican (respectively $1: 10000$ and 1:2000; Dr C Seidenbecher, Magdeburg, Germany).

\section{Real-Time Quantitative PCR}

Heroin-induced changes in the transcript levels were analyzed from the mPFC of an independent group of rats ( $n=6-7)$ using real-time qPCR as described previously (Van den Oever et al, 2006). Transcript specific primers were designed for Bcan, Tnr, and reference genes GAPDH and NSE (see Supplementary Table S2). For all statistical calculations, the absolute amount of normalized transcript of interest, $\mathrm{C} \times \mathrm{E}^{-\mathrm{Ct}} / \mathrm{NF}\left(\mathrm{C}=10^{7}\right)$ was used.

\section{Immunohistochemistry (IHC)}

The labeling of perineuronal nets using WFA (marker for CSPG positive perineuronal nets; $5 \mu \mathrm{g} / \mathrm{ml}$, SigmaAldrich), ECM proteins, parvalbumin and CAMKII-alpha immunoreactive neurons was performed in naïve rats $(n=3)$ according to standard protocols (for details; Supplementary Methods) using the following primary antibodies: rabbit anti-brevican (1:5000), mouse antiTenascin-R (1:1000), mouse anti-parvalbumin, (1:1000 Sigma-Aldrich) and mouse anti-CAMKII-alpha (1:200 pierce antibodies).

\section{Electrophysiology}

Separate groups of rats ( $n=5$ per group) trained to selfadminister heroin or saline were used for recordings of IPSCs following both cue and no cue exposure tests. Immediately following a $30 \mathrm{~min}$ extinction or reinstatement test, rats were decapitated and brains were rapidly removed and put in ice-cold artificial cerebrospinal fluid (ACSF) which contained (in $\mathrm{mM}$ ): $\mathrm{NaCl} 125 ; \mathrm{KCl} 3 ; \mathrm{NaH}_{2} \mathrm{PO}_{4}$ 1.25; $\mathrm{MgSO}_{4} 3 ; \mathrm{CaCl}_{2} 1 ; \mathrm{NaHCO}_{3}$ 26; glucose 10; osmolarity: 300 mOsm.

Coronal mPFC slices of $350 \mu \mathrm{m}$ thickness were prepared in sucrose-containing ACSF consisting of (in $\mathrm{mM}$ ) $\mathrm{KCl} 3.5$; $\mathrm{CaCl}_{2}$ 2.4; $\mathrm{MgSO}_{4} \cdot 7 \mathrm{H}_{2} \mathrm{O}$ 1.3; $\mathrm{KH}_{2} \mathrm{PO}_{4}$ 1.2; Sucrose 215.5; $\mathrm{NaHCO}_{3}$ 26; D-glucose 10. Slices were stored in holding chambers containing normal ACSF consisting of (in $\mathrm{mM}$ ): 
$\mathrm{NaCl} 125 ; \mathrm{KCl} 3 ; \mathrm{NaH}_{2} \mathrm{PO}_{4} 1.25 ; \mathrm{MgSO}_{4} 2 ; \mathrm{CaCl}_{2} 1 ; \mathrm{NaHCO}_{3}$ 26; glucose 10 , bubbled with carbogen gas $\left(95 \% \mathrm{O}_{2} / 5 \%\right.$ $\mathrm{CO}_{2}$ ). Pyramidal neurons and interneurons in layer II/III in the $\mathrm{mPFC}$ were visualized using either Hoffman modulation or differential interference contrast microscopy and wholecell recordings from pyramidal neurons were made using Multiclamp 700A amplifier (Axon Instruments, CA), digitized by the pClamp software (Axon), and later analyzed offline using Synaptosoft (Delaware, GA) software. The pipette medium contained (in $\mathrm{mM}$ ) Cs gluconate 120; $\mathrm{CsCl}$ 10; $\mathrm{NaCl}$ 8; $\mathrm{MgATP} 2$; phosphocreatine 10; EGTA 0.2; HEPES 10; Tris GTP 0.3 , QX 314-Cl 1. For detection of IPSCs, neurons were held at $0 \mathrm{mV}$ potential. Statistical analysis was performed on individual neurons using a twofactor ANOVA with treatment (saline/heroin) and cue (cue/ no cue) as between subject factors.

\section{Ventricular injections of FN-439}

Rats ( $n=7-9$ per group) were implanted with jugular vein catheters as described above and for injection into the right lateral ventricle, a guide cannula (Plastics One 26-gauge) was stereotaxically placed against the dura with the coordinates anterior posterior $-0.8 \mathrm{~mm}$ and lateral $1.3 \mathrm{~mm}$ relative to Bregma and thereafter securely fastened to the skull by acrylic dental cement. FN-439 (35 $\mu$ g; Sigma Aldrich, Zwijndrecht, The Netherlands) was injected $90 \mathrm{~min}$ before the first reinstatement test (Brown et al, 2007). The microinjector (30-gauge) penetrated $3.7 \mathrm{~mm}$ below the dura and the compound was infused in a volume of $5 \mu$ l over $60 \mathrm{~s}$. The injector was left in situ for another $120 \mathrm{~s}$. For immunoblotting after reinstatement testing, rats were decapitated $3 \mathrm{~h}$ after the second reinstatement test and brains were rapidly frozen and stored until further use.

\section{RESULTS}

\section{iTRAQ-Based Proteomics: Regulation of ECM Proteins}

We trained animals to self-administer heroin or saline for subsequent biochemical analysis as described above (Figure 1a). Two-factor analysis (repeated measures) for responses in the active (heroin-paired) hole revealed a significant effect for training condition $\left(\mathrm{F}_{1,24}=7.99\right.$; $p<0.009)$, session $\left(\mathrm{F}_{15360}=12.59 ; p<0.001\right)$, and session $\times$ training condition $\left(\mathrm{F}_{15360}=7.77 ; p=0.001\right)$. To identify relatively persistent heroin-induced changes in the synaptic proteome, the mPFC was dissected from the rats 21 days after the final heroin self-administration session (Figure 1b). Changes in a broad range of synaptic and synapse-associated proteins were quantified using isobaric Tags for Relative and Absolute Quantification (iTRAQ) combined with two-dimensional liquid chromatography and tandem mass spectrometry (2D LC-MS/MS), a powerful and reliable technology for quantification of neuronal proteins simultaneously from multiple samples ( $\mathrm{Hu}$ et al, 2006; Li et al, 2007; Van den Oever et al, 2008). To isolate mPFC synaptic membrane fractions and to perform a duplicate measurement within a single iTRAQ experiment, two pools of heroin self-administration and two pools of saline self-administration (three animals per pool) were generated (Supplementary Figure S1). In total 486 proteins were identified, with an average heroin-to-saline ratio of all quantified proteins of approximately 0 (respectively -0.01 $\left.\left(\log _{2}\right)\right)$ and a $\sigma$ of 0.13 . Long-term forced abstinence from heroin self-administration resulted in significant $(p<0.05)$ and substantial regulation ( $>$ average $\pm \sigma$ ) of 27 proteins in mPFC that could be classified into proteins involved in cell adhesion and ECM proteins, signal transduction, neurotransmitter secretion, regulation of cell growth, and metabolism (Table 1). In terms of magnitude of regulation, proteins of the ECM (Tenascin-R (Tnr), Brevican (Bcan), and Hyaluronan and proteoglycan link protein 1 (Hapln1)) stood out. As these proteins have been reported to have an important role in neuronal plasticity but have not been described before in terms of regulation by drugs of abuse, they were selected for in-depth studies and confirmation by immunoblotting.

\section{Confirmation of Regulation by Immunoblotting and Real-Time Quantitative PCR}

Immunoblotting and real-time quantitative PCR (qPCR) were used to validate regulations found with iTRAQ-based

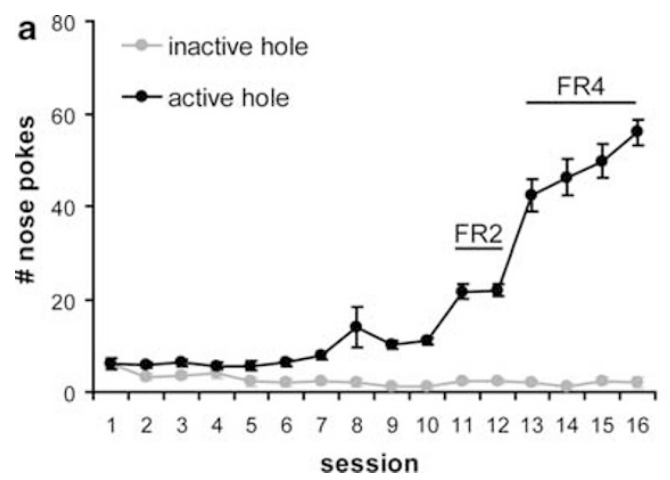

b

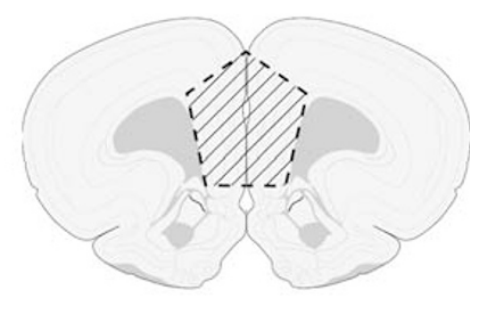

Figure I Acquisition of heroin self-administration and mPFC dissection. (a) Heroin self-administrating rats developed a stable preference for the active

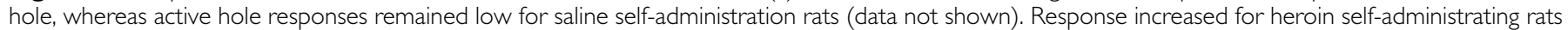

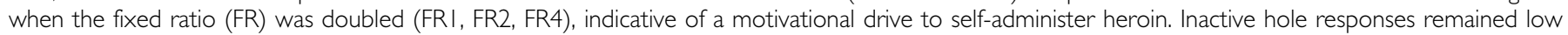

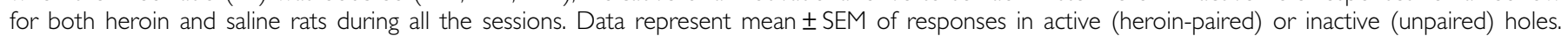
(b) Approximate anatomical dissection limits of the mPFC (between bregma 3.7-2.7) are depicted by the hatched area. 
Table I Heroin-Induced Alteration of Synaptic Protein Levels in mPFC

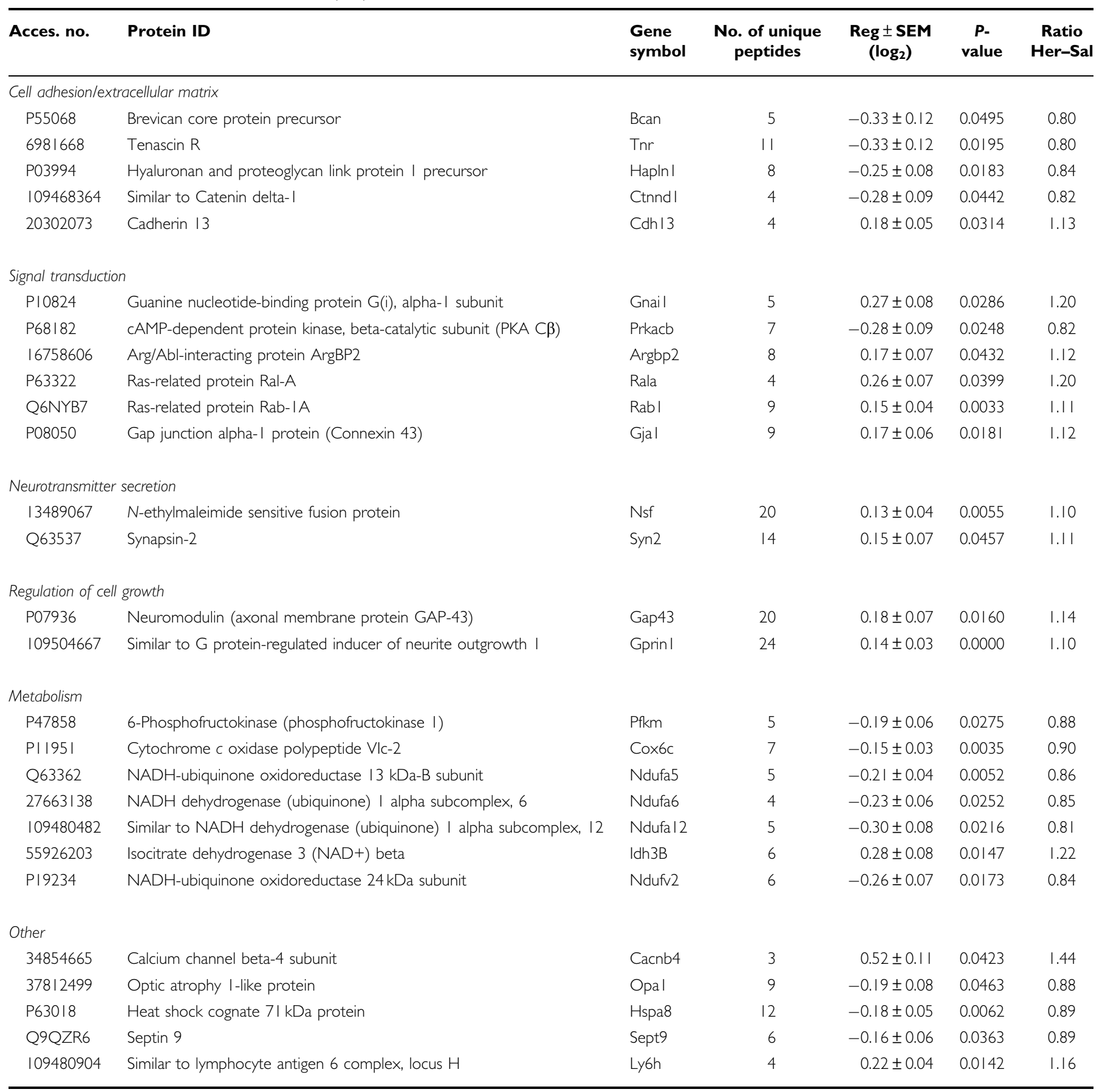

Proteins (indicated by name and gene symbol) that showed a significant change $(p<0.05)$ with a regulation $\left(\right.$ ratio; $\left.\log _{2}\right)$ that is more than the average $\pm \sigma$ classified based on their function (Gene Ontology). Accession numbers were derived from the rat SwissProt and NCBI database. Ratios are based on the average iTRAQ area abundance of two independent synaptic membrane fractions for each treatment.

proteomics at the protein and transcript level. In line with the observed downregulation of ECM proteins Bcan and Tnr by iTRAQ analysis, immunoblotting revealed a $49 \%$ decrease in the $160 \mathrm{Tnr}$ isoform $\left(t_{4}=3.33, p=0.03\right)$ and a $41 \%$ decrease in the abundance of the Bcan $145 \mathrm{kDa}$ isoform $\left(t_{4}=2.91, p=0.04\right)$ in $\mathrm{mPFC}$ synaptic fractions during longterm forced abstinence from heroin self-administration as determined in an independent group of rats (Figure 2a and b). Synaptic membrane expression of Tnr $180 \mathrm{kDa}$ was decreased in heroin-administered animals, but did not reach significance $\left(t_{4}=2.43, p=0.07\right)$. Abundance of the membrane-bound GPI-anchored $120 \mathrm{kDa}$ Bcan isoform (Seidenbecher et al, 1995) was unaltered. Levels of the corresponding proteins in total mPFC homogenate as well as transcript levels of Bcan and Tnr in mPFC did not differ after heroin self-administration (Figure $2 b$ and $c$ ), indicating that the observed downregulation of these proteins occurred specifically at the synapse. 
a

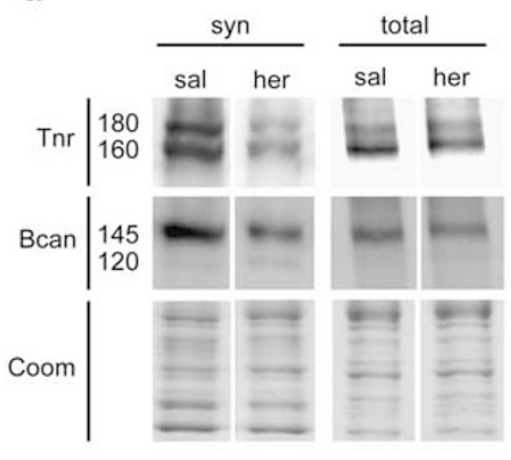

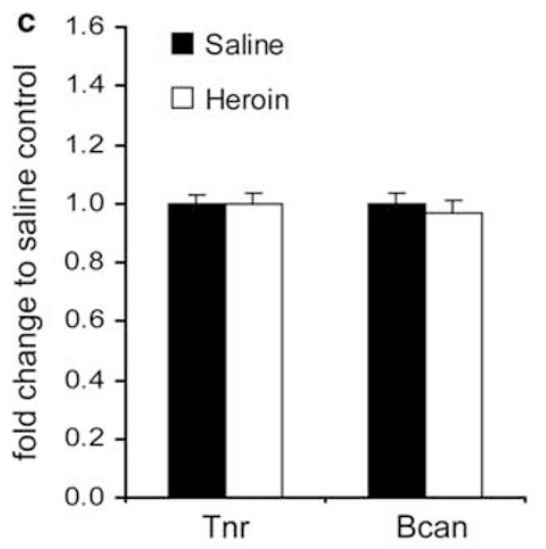

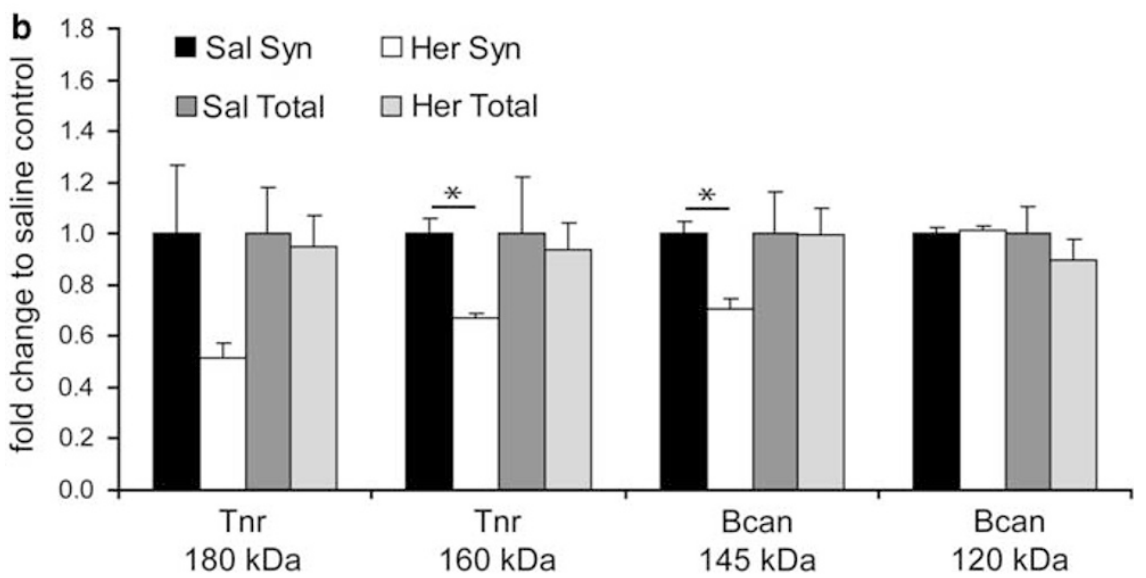

Figure 2 Protein level changes of ECM proteins Bcan and Tnr confirmed by immunoblotting. (a) Synaptic protein (Syn) and total protein (Total) fractions were isolated from the mPFC of a group of animals (independent of iTRAQ experiment) and analyzed by immunoblotting using antibodies against Tnr and Bcan. Representative examples are shown. Levels of immunodetected bands were normalized to proteins on a coomassie (coom)-stained gel that was run in parallel. (b) Optical densities (blot, coomassie) were analyzed and set to the saline control. A significant decrease was detected in the level of Tnr I $60 \mathrm{kDa}$ isoform and Bcan $145 \mathrm{kDa}$ isoform in synaptic fractions of the mPFC. Tnr and Bcan protein levels were unaltered in the total mPFC homogenate. (c) The mRNA level of Tnr and Bcan was unaltered in the mPFC during forced abstinence from heroin self-administration. All data are mean \pm SEM. $* p<0.05$ (Student $t$-test).

To gain more insight into the role of ECM proteins in extinction and reinstatement of heroin seeking, we determined whether expression of synaptic ECM proteins was also altered after 21 days of extinction from heroin self-administration and immediately after a cue-induced reinstatement test (30 $\mathrm{min})$. Exposure to heroin-conditioned cues induced robust heroin seeking (Figure 3). We observed a significant difference for responses in the active hole between groups $\left(t_{16}=3.25, p=0.005\right)$. Inactive nose pokes were also significantly different between groups, but remained low ( $<10$ responses; $t_{16}=3.50, p=0.003$ ). Similar to abstinence from heroin self-administration, one-way ANOVA with post-hoc analysis revealed a significant reduction in the level of $\mathrm{Bcan} 145 \mathrm{kDa}\left(30 \% ; \mathrm{F}_{2,6}=16.2\right.$; $p=0.004)$ after extinction of heroin self-administration and a similar (non-significant) trend for decrease in Tnr 180 and $160 \mathrm{kDa}(\sim 33 \%, p>0.05)$ (Figure 4a). Strikingly, we found that synaptic Bcan protein levels following exposure to heroin-conditioned cues were equivalent to the saline control group, indicating that cue-induced reinstatement of heroin seeking resulted in a rapid recovery of Bcan in the mPFC. Glutamatergic projections from the mPFC to the striatum have a critical role in reinstatement of drug seeking (Kalivas et al, 2005; LaLumiere and

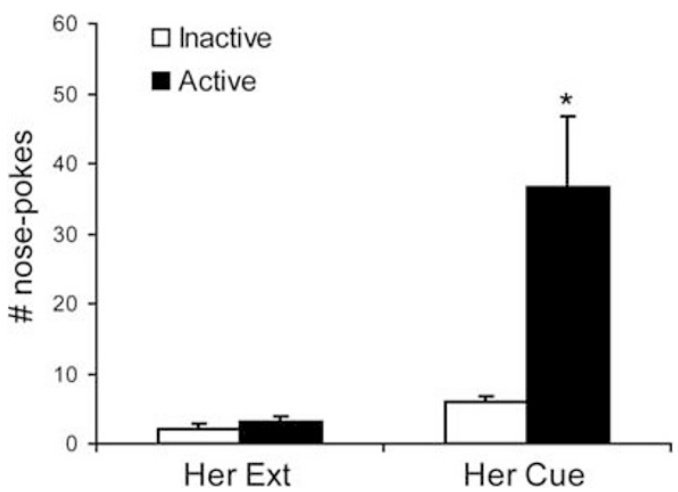

Figure 3 Cue-induced reinstatement of heroin seeking. Exposure to the compound visual and auditory cue reinstated responding in the active (previously heroin-paired) hole. Bars represent mean number of nose pokes \pm SEM. $* 0<0.0$ I (Students $t$-test) for between group difference of responses in active hole and within group difference of active and inactive responses.

Kalivas, 2008; Peters et al, 2009). Therefore, we determined whether Bcan and Tnr were also regulated in the NAc and dorsal striatum (Figure $4 \mathrm{~b}$ and $\mathrm{c}$ ). Indeed, levels of ECM proteins in synaptic membrane fractions were also 
a

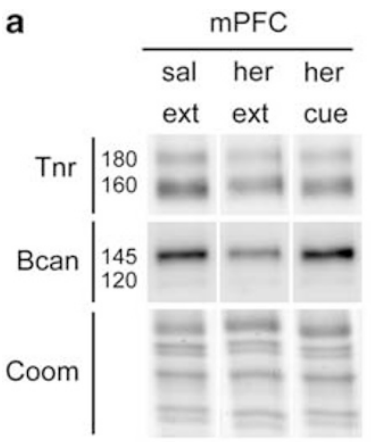

b
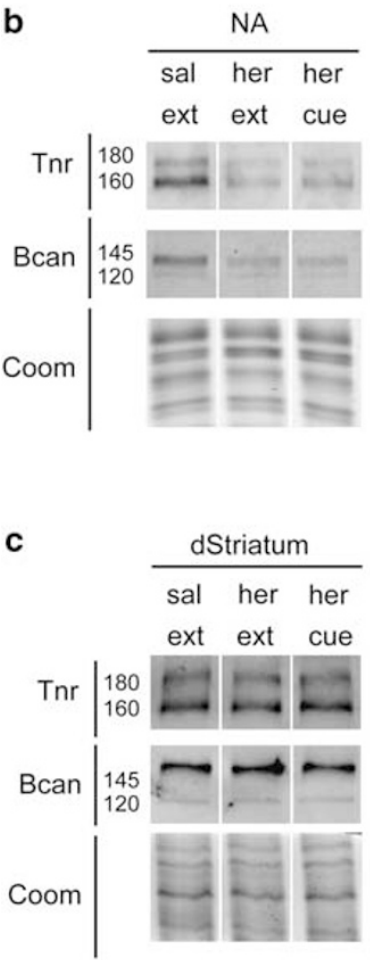
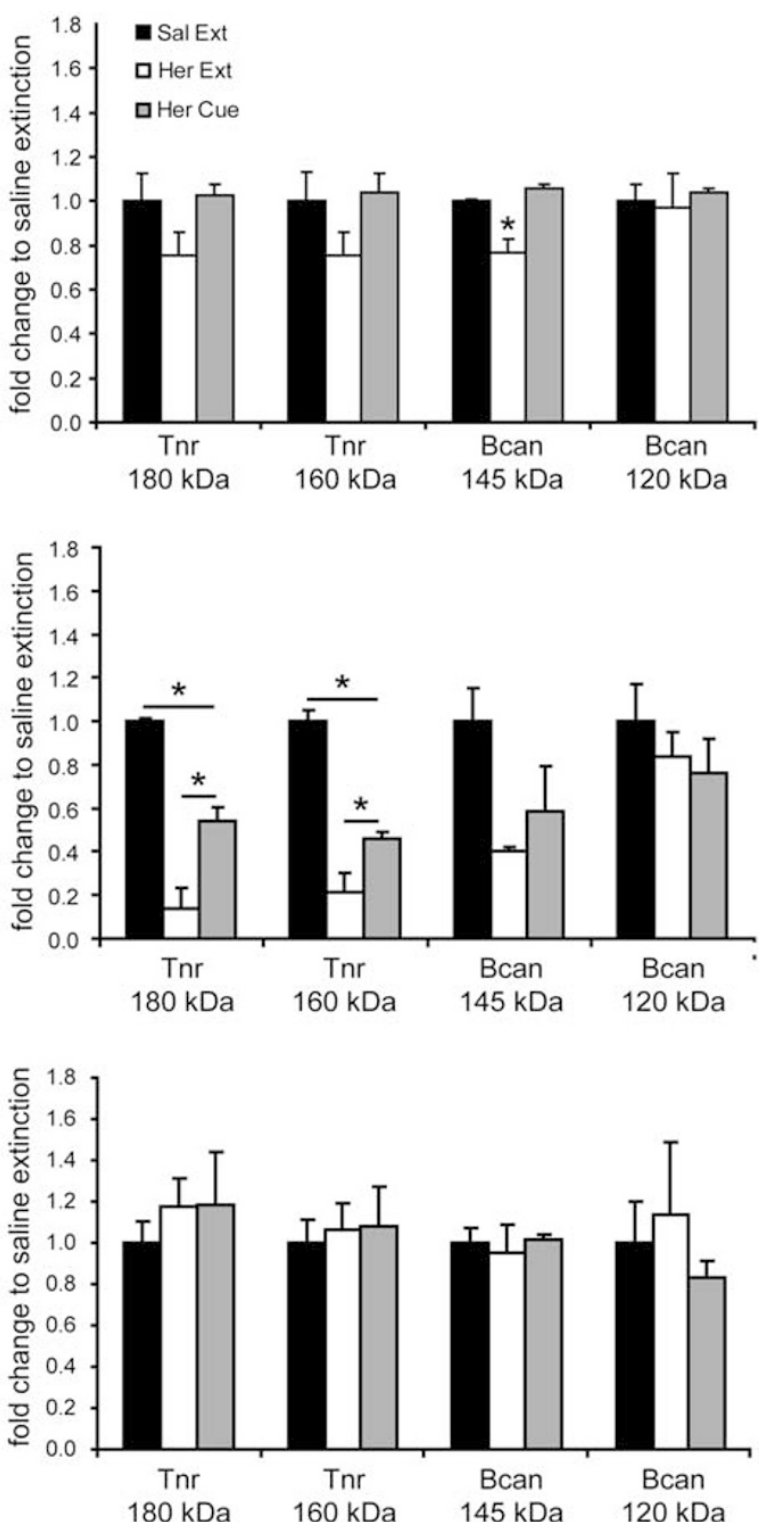

Figure 4 ECM proteins are also downregulated after extinction of heroin self-administration. We compared levels of Bcan and Tnr proteins in synaptic fractions of the mPFC, NAc, and dorsal striatum (dStriatum) between animals that underwent saline or heroin extinction, and heroin extinction animals that were re-exposed to heroin-conditioned cues $(30 \mathrm{~min})$. Representative examples are depicted on the left side. (a) We observed a significant reduction in the synaptic protein levels of Bcan ( $45 \mathrm{kDa} ; p<0.05)$ and a similar (non-significant) trend for decrease in Thr I80 and I60 kDa ( $p>0.05)$ levels after extinction of heroin self-administration. The abundance of Bcan $145 \mathrm{kDa}$ did not differ between saline animals and heroin animals that were cue-exposed. Similar to levels during abstinence from heroin self-administration, the level of the Bcan $120 \mathrm{kDa}$ isoform was not altered. (b) In the NAc, the levels of Tnr I80 and $160 \mathrm{kDa}$ were significantly $(p<0.00 \mathrm{I})$ different, with post-hoc analysis revealing a significant difference between all groups. The level of Bcan I $45 \mathrm{kDa}$ followed a similar pattern but ANOVA analysis only reached near significance $(p=0.074)$. (c) Abundance of all Bcan and Tnr isoforms in synaptic fractions of the dorsal striatum was not significantly different. All data are mean \pm SEM. $* 0<0.05$ (one-way ANOVA).

reduced in the NAc, with a significant reduction in Tnr $\quad 180 \mathrm{kDa} \quad\left(\mathrm{F}_{2,6}=46.7 ; \quad p<0.001\right)$ and $160 \mathrm{kDa}$ $\left(\mathrm{F}_{2,6}=40.3 ; p<0.001\right)$ abundance after extinction of heroin self-administration $(\sim 14 \%$ of control levels, $p<0.05)$. Similar to the mPFC, cue-induced reinstatement was paralleled by a significant increase in Tnr levels in the NAc, although the recovery was not complete (compared with saline control). We observed a trend $(40 \%$ of control levels; $\left.\mathrm{F}_{2,6}=4.161 ; p=0.07\right)$ for reduction in Bcan expression in the NAc that was also partially restored after cue exposure. Both Tnr and Bcan protein levels were unaltered in synaptic fractions of the dorsal striatum, indicating that the adaptation of ECM proteins is brain region-specific.

\section{Cellular Localization of Tnr and Bcan in the mPFC}

Previously, a direct interaction between Bcan and Tnr (Aspberg et al, 1997) and colocalization of Bcan and Tnr immunoreactivity in perineuronal nets in mid- and hindbrain was found (Hagihara et al, 1999). To establish that Bcan and Tnr colocalize in perineuronal nets around mPFC neurons, we performed a double staining for both proteins on the brain sections of naïve rats. Although Tnr 

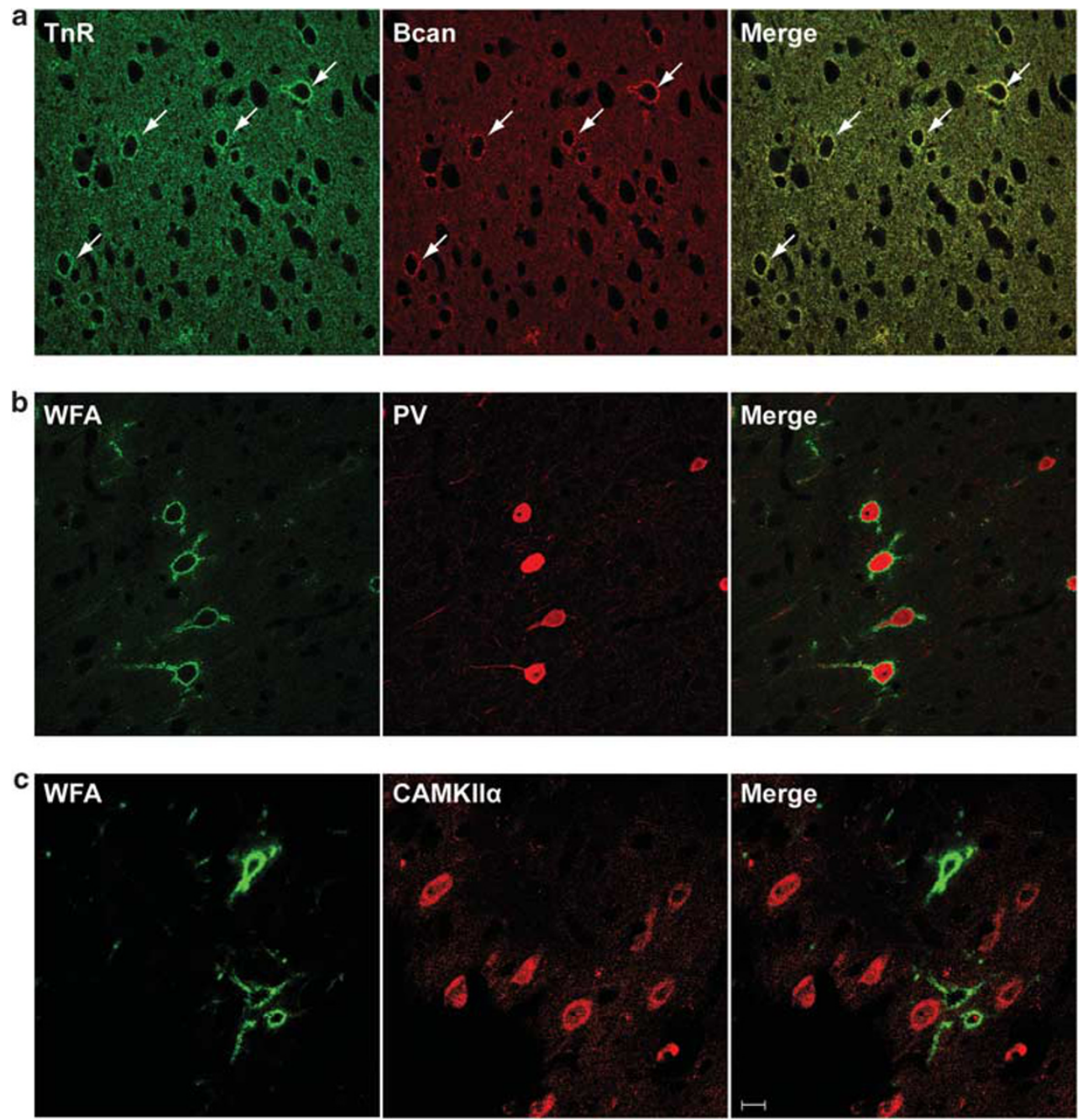

Figure 5 Immunohistochemical identification of ECM proteins in the mPFC. (a) Colocalization of Tnr and Bcan in perineuronal nets in the mPFC. Sections were double-stained using Thr (green) and Bcan (red) specific antibodies and analyzed by confocal microscopy. Immunoreactivity of Tnr and Bcan is colocalized (merged image) in perineuronal nets (white arrows) surrounding a subset of neurons in the anterior cingulate, prelimbic, and infralimbic area of the mPFC. $(b+c)$ Biotinylated-WFA (green) was used to detect chondroitin sulfate proteoglycan-containing perineuronal nets in combination with a PV-specific antibody (red) or CAMKIl $\alpha$ antibody (red). Throughout all areas of the mPFC, perineuronal nets were associated with the majority of PV-expressing interneurons (b), but never with CAMKIl-positive pyramidal neurons (c). Scale bar: $20 \mu \mathrm{m}$.

and Bcan immunoreactivity could be observed at low levels throughout the entire frontal cortex, we observed an intense staining and complete overlap of Bcan and Tnr proteins condensed in perineuronal nets surrounding a subset of neurons within the mPFC (Figure 5a). Moreover, PNN staining of Bcan colocalized with that of wisteria floribunda agglutinin (WFA; Supplementary Figure S2), an ubiquitous marker for chondroitin sulfate proteoglycan positive perineuronal nets (Bruckner and Grosche, 2001; Pizzorusso et al, 2002).

Next, identification of the neuronal subtypes covered by perineuronal nets in $\mathrm{mPFC}$ was performed using WFA combined with the GABAergic interneuron marker parvalbumin $(\mathrm{PV})$ and the excitatory neuron marker calmodulindependent kinase II alpha (CAMKII $\alpha$ ). WFA-positive perineuronal nets mainly surround PV-expressing interneurons in neocortex (Hartig et al, 1992), but some perineuronal nets envelope pyramidal neurons, the frequency of which differs between various regions of the cortex and even within subfields of cortical areas (Wegner et al, 2003; Alpar et al, 2006). We found that WFA-positive perineuronal nets in the infralimbic, prelimbic, and anterior cingulate area of the $\mathrm{mPFC}$ always localized around the majority of PV-expressing interneurons (Figure $5 \mathrm{~b}$ and Supplementary Figure S2). Colocalization with CAMKIIalpha was never observed (Figure 5c). This indicates that mPFC pyramidal neurons are not surrounded by perineuronal nets, and implies that the observed change in ECM proteins occurred specifically at GABAergic interneurons.

\section{GABAergic Transmission is Increased after Cue-Induced Reinstatement}

The observation that ECM proteins enriched around GABAergic interneurons in the $\mathrm{mPFC}$ are regulated after cessation of heroin self-administration and re-exposure to heroin-conditioned cues suggests that GABAergic interneuron activity may have a role in cue-induced reinstatement. This is supported by our previous observation that increasing GABAergic transmission in the MPFC enhances 
cue-induced reinstatement of heroin-seeking behavior (Schmidt et al, 2005). Therefore, we investigated whether GABAergic synaptic transmission to mPFC pyramidal neurons was altered after extinction of heroin self-administration and immediately after a cue-induced reinstatement test. Animals with a history of saline self-administration served as controls. As PV-expressing interneurons are relatively sparse but target multiple pyramidal neurons in the mPFC (Couey et al, 2007), we recorded inhibitory network activity from mPFC pyramidal neurons. We monitored the spontaneous inhibitory synaptic activity received by these neurons, which most likely reflects the activity of a number of inhibitory interneurons. Spontaneous inhibitory postsynaptic currents (sIPSCs) were monitored in acute mPFC brain slices from rats that were exposed or not exposed to heroin-conditioned cues (30 min). We found that the sIPSC frequency was almost doubled in animals re-exposed to heroin-conditioned cues
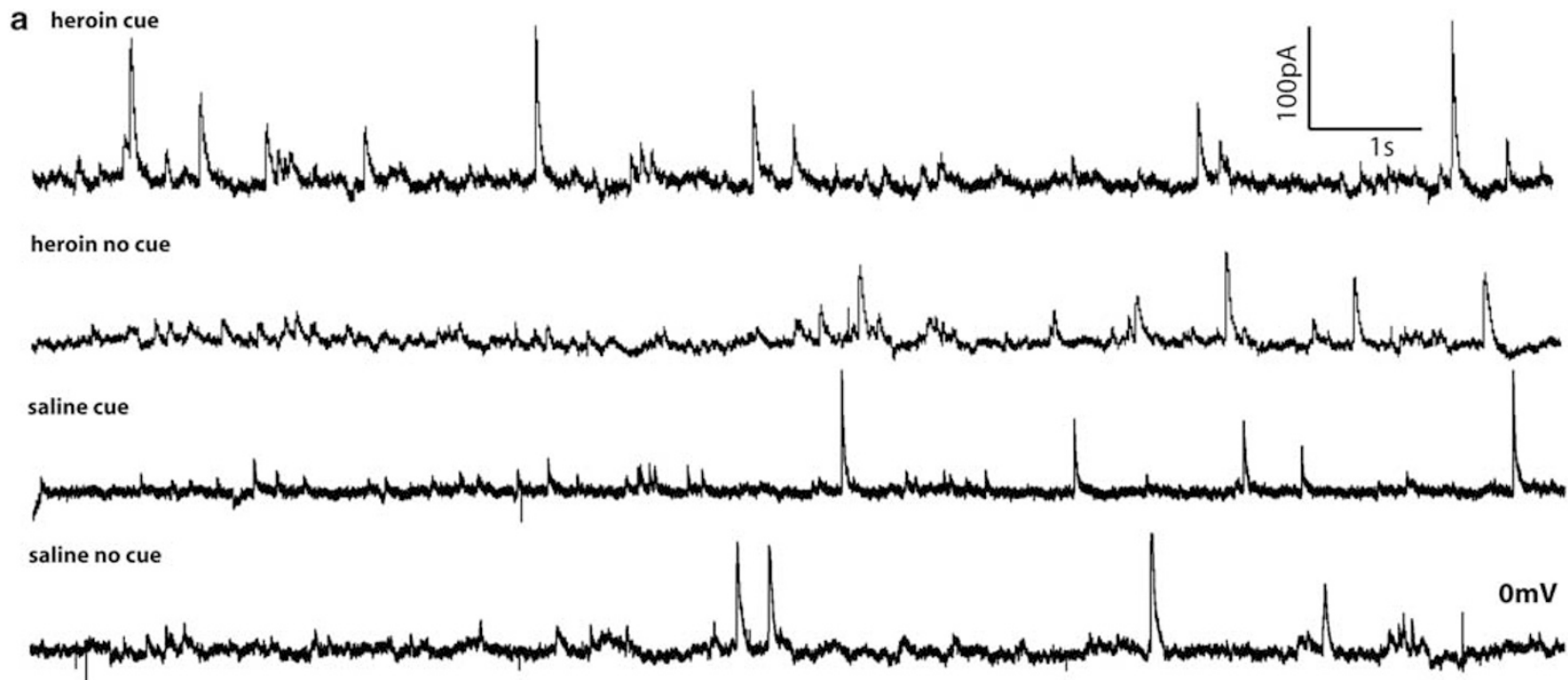

b
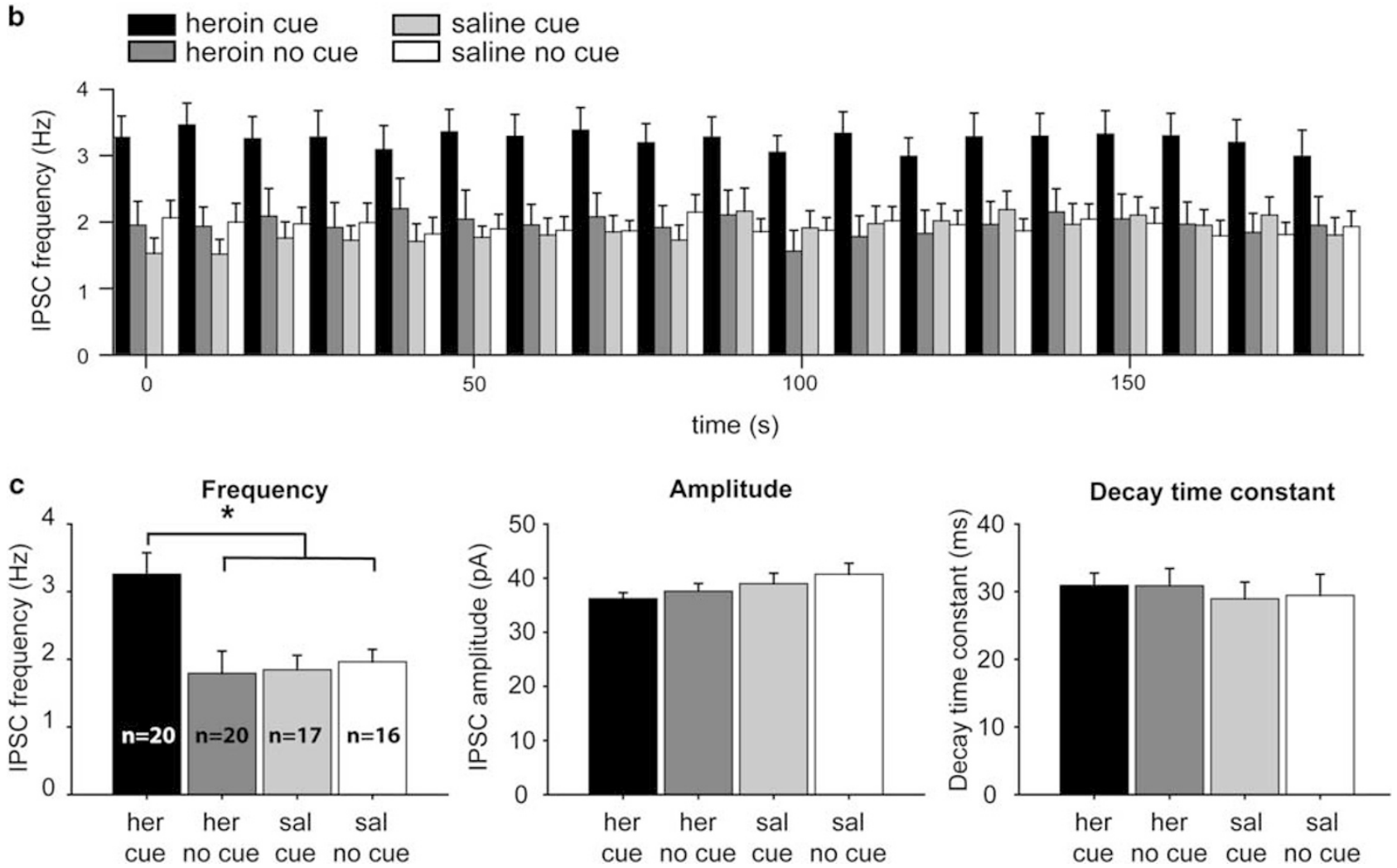

Figure 6 Cue-induced enhancement of GABAergic inhibition of mPFC pyramidal neurons. (a) Example traces of whole-cell recordings from mPFC pyramidal neurons in control and heroin self-administration animals ( $n=5$ per group) that were re-exposed (cue) or not exposed (no cue) to the cues. Number of neurons in each group: Heroin cue, $n=20$; Heroin no cue, $n=20$; Saline cue, $n=17$; Saline no cue, $n=16$. (b) Average IPSC frequency in all neurons recorded during a 3-min period (I0 s bins). (c) Summary data and statistical analysis: average IPSC frequency was significantly higher in heroin animals on cue re-exposure $(* 0.007)$. IPCS amplitude and decay time constant remained unaltered $(p>0.05)$ on cue re-exposure. Data represent mean \pm SEM. 
(Figure 6). A two-factor ANOVA with treatment (heroin/ saline) and cue (cue/no cue) as between factors revealed a significant treatment effect $\left(\mathrm{F}_{1,72}=4.78 ; p=0.03\right)$, an effect of cue $\left(F_{1,72}=5.74, p=0.02\right)$, and an interaction for treatment and cue $\left(\mathrm{F}_{1,72}=7.73, p=0.01\right)$. The frequency of sIPSCs did not differ between heroin self-administration animals that were not cue-exposed and saline control animals (Figure 6c), indicating that specifically the presentation of heroin-conditioned cues increased the inhibition of mPFC pyramidal neurons. sIPSC amplitude and decay-time constant were unchanged $(p>0.05)$ by heroin self-administration and cue presentation (Figure $6 c$ ).

\section{FN-439 Attenuates Cue-Induced Heroin Seeking}

Degradation and remodeling of the ECM is determined by the action of MMPs, a group of zinc-containing proteolytic enzymes, and their endogenous antagonists, the tissue inhibitors of MMPs (Malemud, 2006). In order to show a direct relationship between the downregulation of ECM proteins in the $\mathrm{mPFC}$ and NAc, and reinstatement of heroin seeking, we injected animals with the broad-spectrum metalloproteinase inhibitor FN-439 (Odake et al, 1994), through intracerebral ventricular (ICV) microinjection $90 \mathrm{~min}$ before the first reinstatement test (Brown et al, 2007). A second reinstatement test was performed $24 \mathrm{~h}$ later. Presentation of cues in vehicle-treated rats reliably reinstated responding in the active hole both on the first and on the second test day; however, FN-439-treated animals showed an overall reduction in cue-induced reinstatement of heroin seeking (Figure 7a). A repeated-measures ANOVA with treatment as between-factor and test as within-factor revealed a significant $F N-439$ treatment effect $\left(F_{1,31}=5.85\right.$, $p=0.03)$, and an effect of test $\left(\mathrm{F}_{1,31}=9.66, p=0.01\right)$, but no interaction between treatment and test. To determine the consequence of the FN-439 treatment on synaptic ECM protein levels, we analyzed Bcan and Tnr levels in mPFC and NAc synaptic membrane fractions $3 \mathrm{~h}$ after the last reinstatement test (Figure $7 \mathrm{~b}-\mathrm{d}$ ). Indeed, in FN-439 treated animals, Tnr $160 \mathrm{kDa}\left(155 \% ; t_{10}=2.33, p=0.04\right)$ and Bcan $145 \mathrm{kDa}\left(185 \% ; t_{10}=2.44, \quad p=0.03\right)$ were present at significantly higher levels compared with vehicle-treated animals in the MPFC (Figure 7c) and to a smaller extent (non-significant) in the NAc (Figure 7d), indicating that restoring levels of ECM proteins prior to a reinstatement test reduced subsequent responding of animals to heroinconditioned cues.

\section{DISCUSSION}

The persistent nature of drug-seeking behavior is thought to be caused by long-lasting alterations in neuronal circuitry involved in motivational and cognitive processing, such as the mPFC and striatum. Here, using an iTRAQ-based
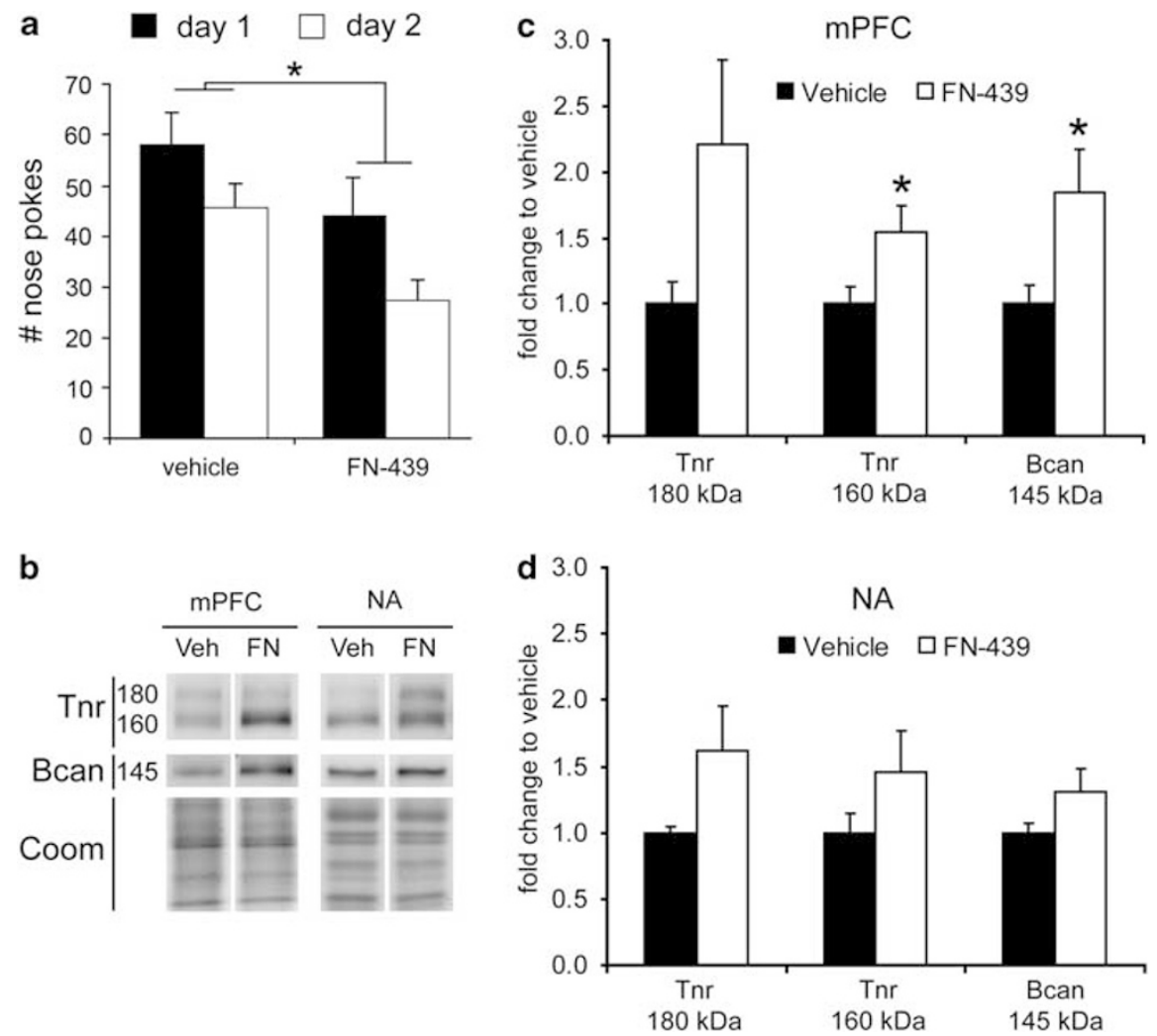

Figure 7 FN-439 treatment attenuates cue-induced heroin seeking and increased ECM protein levels in the mPFC. (a) ICV injection of FN-439attenuated cue-induced heroin seeking as compared with vehicle (ACSF; $n=7-9$ per treatment). Nose-poking in the inactive hole was not altered by FN-439 treatment (data not shown). (b) Three hours after the last reinstatement test, synaptic fractions were isolated from the mPFC of these animals and analyzed with immunoblotting. (c) A significant increase was detected in the levels of Tnr I $60 \mathrm{kDa}$ and Bcan I $45 \mathrm{kDa}$ isoform in the mPFC. (d) Expression of $\mathrm{Tnr}$ and Bcan in the NAc was increased after FN-439 treatment, but did not reach significance $(p>0.05)$. * $p<0.05$. Data represent mean \pm SEM. 
proteomics approach that allows changes in protein levels to be probed directly (Van den Oever et al, 2008), we show that heroin self-administration leads to persistent changes in protein levels in mPFC-synaptic membrane fractions. Regulated proteins were classified into several functional groups, and the functional group of proteins with the most profound change in abundance after heroin self-administration contained several components of the ECM known to condense in perineuronal nets. The regulation of this set of proteins was subsequently confirmed in an independent experiment.

Perineuronal nets are net-like structures of the brain ECM that surround cell bodies, proximal dendrites, and synapses of a subset of neurons in the CNS (Yamaguchi, 2000; Dityatev and Schachner, 2003). During development of the nervous system, the ECM is suggested to have a role in cell adhesion, cell migration, and axon guidance (Bandtlow and Zimmermann, 2000; Berardi et al, 2004), whereas in the adult brain ECM proteins condensed in perineuronal nets are suggested to maintain established neuronal connections (Murakami and Ohtsuka, 2003). Apart from a role in structural plasticity, perineuronal nets might act in the context of buffers for neurotransmitter release, electrical insulation, and growth factor supply of synapses (Yamaguchi, 2000; Dityatev and Schachner, 2003). Degradation of perineuronal nets, by treatment with chondroitinase $\mathrm{ABC}$, results in functional recovery of cortical plasticity (Pizzorusso et al, 2002, 2006) and promotes functional recovery of nervous system injury (Bradbury et al, 2002).

We found that long-term forced abstinence from heroin self-administration is associated with a decrease in the abundance of Bcan, Tnr, hyaluronan, and proteoglycan link protein 1 (Hapln1), all constituents of perineuronal nets, locally at the synapse in the mPFC. Moreover, a similar change in protein levels was observed in synapses of the mPFC and NAc, but not in dorsal striatum, after extinction of heroin self-administration. This suggests that long-term cessation of heroin self-administration is associated with adaptation of the ECM in the MPFC-NAc pathway, a neural circuit that has a pivotal role in relapse to drug seeking (McFarland and Kalivas, 2001; Kalivas et al, 2005; Peters et al, 2008a; Van den Oever et al, 2009). Bcan interacts with its C-type lectin domain with the ECM glycoprotein Tnr (Aspberg et al, 1997). LTP is impaired in mice that lack Bcan or Tnr, implicating a role of perineuronal nets in synaptic plasticity mechanisms (Saghatelyan et al, 2001; Brakebusch et al, 2002). Link proteins, such as Hapln1, are thought to have an important role in formation and stability of perineuronal nets (Carulli et al, 2006). Bcan and Tnr immunoreactivity colocalizes in perineuronal nets in midbrain and hindbrain (Hagihara et al, 1999). Indeed, we observed that throughout the mPFC, Bcan and Tnr always colocalize in perineuronal nets, supporting the observed co-regulated decrease in expression after heroin self-administration and the possibility of interaction of these proteins. Remarkably, we found that levels of Bcan rapidly increase following re-exposure to heroin-associated cues. The specific downregulation of ECM proteins in synaptic membrane fractions suggests that the expression level of these molecules is altered by the activity of locally acting MMPs (Wright and Harding, 2009). Furthermore, locally reduced MMP activity and extrasynaptic redistribution of ECM constituents may underlie the rapid nature of the recovery of ECM protein levels in synaptic fractions of the $\mathrm{mPFC}$ and NAc after exposure to heroinconditioned cues.

In the mPFC, perineuronal nets are associated with PVexpressing GABAergic interneurons. PV-expressing neurons are fast-spiking inhibitory interneurons (Cauli et al, 1997; Kawaguchi and Kondo, 2002). Therefore, adaptation of ECM molecules may lead to an alteration in the structural stability or physiological properties of synapses at fastspiking GABAergic interneurons. Interestingly, GABAergic interneurons in the neocortex exert powerful inhibitory control over the excitatory output of pyramidal neurons (Cowan et al, 1994; Constantinidis et al, 2002). Therefore, it is thought that GABAergic neurotransmission within the $\mathrm{mPFC}$ is an important regulator of inhibitory control over drug-related behavior (McFarland et al, 2003; Steketee, 2005). In this study, we found that cue-induced reinstatement of heroin seeking is associated with almost a doubling of the frequency of inhibitory inputs to $\mathrm{mPFC}$ pyramidal neurons, pointing to increased GABAergic interneuron activity on cue exposure. At the same time, the decay-time constant and amplitude of IPSCs were unchanged, arguing against a post-synaptic mechanism in mPFC pyramidal neurons. Increased GABAergic transmission on exposure to heroin-conditioned cues is in line with our previous observation that infusion of GABA receptor agonists muscimol and baclofen in the prelimbic area enhances cue-induced reinstatement of heroin seeking (Schmidt et al, 2005). Similarly, cocaine-seeking assessed with the conditioned place preference model is accompanied by robust activation of GABAergic interneurons, as opposed to pyramidal neurons, in the prelimbic area (Miller and Marshall, 2004). In addition, mPFC GABAergic transmission appears to be critically involved in cocaine sensitization (Steketee, 2005) and reinstatement of cocaine seeking (McFarland et al, 2003; Peters et al, 2008b). When infused in the infralimbic area, GABA agonists augment cocaine seeking under extinction conditions by reducing glutamatergic output to the NAc shell (Peters et al, 2008a). Although changes in ECM proteins were not analyzed at the subregional level within the $\mathrm{mPFC}$, potentially, molecular changes in ECM constituents may account for the enhanced responsivity of ventral $\mathrm{mPFC}$ (comprising the ventral prelimbic and infralimbic area) GABAergic interneurons to heroin-conditioned cues, thereby increasing inhibition of ventral $\mathrm{mPFC}$ pyramidal neurons during cue-induced reinstatement.

The final step in this study was to determine whether the observed ECM changes are indeed involved in vulnerability to relapse to heroin seeking. To that end, we counteracted the heroin self-administration-induced downregulation of the ECM in mPFC and NAc by central application of the MMP inhibitor FN-439 (Odake et al, 1994) prior to a reinstatement test. Inhibition of MMP activity increased the synaptic levels of Tnr and Bcan in mPFC (and to some extent in NAc) and attenuated cue-induced reinstatement of heroin seeking. Although inhibition of MMP activity in other brain regions other than the MPFC and NAc may have contributed to this effect as well, it suggests that downregulation of ECM proteins after cessation of heroin selfadministration renders animals more sensitive to reinstatement 
by heroin-conditioned cues. The present observation is in line with the finding that inhibition of MMP activity impairs reinstatement of cocaine seeking in a conditioned place preference paradigm (Brown et al, 2007). However, the decrease in heroin seeking appears to be in contrast with the rapid upregulation of Bcan in the MPFC and Tnr in the NAc that we observed following a reinstatement test. Assuming that the elevation in ECM protein abundance has a role in cue-induced heroin seeking, we speculate that this rapid increase in ECM protein levels only affects heroin seeking (or is more effective) when initial ECM levels are low, such as observed during forced abstinence/extinction. Hence, recovering ECM protein levels by FN-439 treatment prior to a reinstatement test blunts the endogenous increase in ECM levels during reinstatement and may consequently reduce responding on exposure to heroin-conditioned cues. A similar homeostatic mechanism involving extracellular glutamate levels in the NAc core is thought to underlie reinstatement of cocaine seeking (Kalivas, 2009). Alternatively, the acute upregulation of ECM proteins may not be directly related to cue-induced heroin seeking, but may be a compensatory mechanism to counteract the increased inhibitory network activity during reinstatement. Future research should clarify whether this rapid accumulation of ECM proteins at synapses in the MPFC and NAc is long lasting and how it contributes to extinction/reinstatement and GABAergic transmission.

Potentially, the modulation of ECM proteins condensed around GABAergic interneurons in the $\mathrm{mPFC}$ may represent a novel mechanistic element to augment GABAergic inhibition of pyramidal neuron activity during cue-induced relapse to heroin seeking. This, together with our previous observation that synaptic strength in ventral mPFC pyramidal neurons is reduced after exposure to heroinconditioned cues (Van den Oever et al, 2008), suggests that excitatory output from the ventral mPFC is diminished. Consequently, response inhibition to drug-associated cues may be impaired (Peters et al, 2008a; Van den Oever et al, 2009). Moreover, the observation that inhibition of MMP activity also impairs acquisition and reconsolidation of cocaine conditioned place preference (Brown et al, 2007), suggests that long-term adaptation of the ECM may have a more general role in the persistence of drug-seeking behavior.

\section{CONCLUSIONS}

Here, we show that long-term cessation of heroin selfadministration is associated with reduced levels of ECM proteins locally at the synapse in the MPFC and NAc. In the mPFC, these ECM proteins are condensed in perineuronal nets surrounding synapses at fast-spiking GABAergic interneurons, and cue-induced reinstatement is accompanied by an increase in GABAergic transmission. Our data suggest that ECM proteins are part of a mechanism that alters cue-conditioned responsivity of mPFC GABAergic interneurons and contributes to vulnerability to relapse to heroin seeking after prolonged cessation of heroin selfadministration. A better understanding of these molecular mechanisms is of ultimate importance for the discovery of new entry points into enabling synaptic flexibility: ie, providing plasticity and renewed learning at 'static synapses' under conditions of psychiatric disease, including drug addiction.

\section{ACKNOWLEDGEMENTS}

MCVDO and BRL contributed equally to the paper. We thank Yvonne Gouwenberg for technical support. This research is funded by ZonMw, the Netherlands Organization for Health Research and Development, grant 40-0081298-09005, and by funds of the Center for Medical Systems Biology (CMSB) to ABS and KWL.

\section{DISCLOSURE}

The authors declare no conflict of interest.

\section{REFERENCES}

Alpar A, Gartner U, Hartig W, Bruckner G (2006). Distribution of pyramidal cells associated with perineuronal nets in the neocortex of rat. Brain Res 1120: 13-22.

Aspberg A, Miura R, Bourdoulous S, Shimonaka M, Heinegard D, Schachner M et al (1997). The C-type lectin domains of lecticans, a family of aggregating chondroitin sulfate proteoglycans, bind tenascin-R by protein-protein interactions independent of carbohydrate moiety. Proc Natl Acad Sci USA 94: 10116-10121.

Bandtlow CE, Zimmermann DR (2000). Proteoglycans in the developing brain: new conceptual insights for old proteins. Physiol Rev 80: 1267-1290.

Berardi N, Pizzorusso T, Maffei L (2004). Extracellular matrix and visual cortical plasticity: freeing the synapse. Neuron 44: 905-908.

Bradbury EJ, Moon LD, Popat RJ, King VR, Bennett GS, Patel PN et al (2002). Chondroitinase $\mathrm{ABC}$ promotes functional recovery after spinal cord injury. Nature 416: 636-640.

Brakebusch C, Seidenbecher CI, Asztely F, Rauch U, Matthies H, Meyer H et al (2002). Brevican-deficient mice display impaired hippocampal CA1 long-term potentiation but show no obvious deficits in learning and memory. Mol Cell Biol 22: 7417-7427.

Brown TE, Forquer MR, Cocking DL, Jansen HT, Harding JW, Sorg BA (2007). Role of matrix metalloproteinases in the acquisition and reconsolidation of cocaine-induced conditioned place preference. Learn Mem 14: 214-223.

Bruckner G, Grosche J (2001). Perineuronal nets show intrinsic patterns of extracellular matrix differentiation in organotypic slice cultures. Exp Brain Res 137: 83-93.

Carulli D, Rhodes KE, Brown DJ, Bonnert TP, Pollack SJ, Oliver K et al (2006). Composition of perineuronal nets in the adult rat cerebellum and the cellular origin of their components. J Comp Neurol 494: 559-577.

Cauli B, Audinat E, Lambolez B, Angulo MC, Ropert N, Tsuzuki K et al (1997). Molecular and physiological diversity of cortical nonpyramidal cells. J Neurosci 17: 3894-3906.

Constantinidis C, Williams GV, Goldman-Rakic PS (2002). A role for inhibition in shaping the temporal flow of information in prefrontal cortex. Nat Neurosci 5: 175-180.

Couey JJ, Meredith RM, Spijker S, Poorthuis RB, Smit AB, Brussaard $\mathrm{AB}$ et al (2007). Distributed network actions by nicotine increase the threshold for spike-timing-dependent plasticity in prefrontal cortex. Neuron 54: 73-87.

Cowan RL, Sesack SR, Van Bockstaele EJ, Branchereau P, Chain J, Pickel VM (1994). Analysis of synaptic inputs and targets of physiologically characterized neurons in rat frontal cortex: 
combined in vivo intracellular recording and immunolabeling. Synapse 17: 101-114.

Dityatev A, Schachner M (2003). Extracellular matrix molecules and synaptic plasticity. Nat Rev Neurosci 4: 456-468.

Dong Z, Cao J, Xu L (2007). Opiate withdrawal modifies synaptic plasticity in subicular-nucleus accumbens pathway in vivo. Neuroscience 144: 845-854.

Epstein DH, Preston KL, Stewart J, Shaham Y (2006). Toward a model of drug relapse: an assessment of the validity of the reinstatement procedure. Psychopharmacology (Berl) 189: $1-16$.

Hagihara K, Miura R, Kosaki R, Berglund E, Ranscht B, Yamaguchi Y (1999). Immunohistochemical evidence for the brevican-tenascin-R interaction: colocalization in perineuronal nets suggests a physiological role for the interaction in the adult rat brain. J Comp Neurol 410: $256-264$.

Hammer Jr RP, Ricalde AA, Seatriz JV (1989). Effects of opiates on brain development. Neurotoxicology 10: 475-483.

Hartig W, Brauer K, Bruckner G (1992). Wisteria floribunda agglutinin-labelled nets surround parvalbumin-containing neurons. Neuroreport 3: 869-872.

Hu J, Qian J, Borisov O, Pan S, Li Y, Liu T et al (2006). Optimized proteomic analysis of a mouse model of cerebellar dysfunction using amine-specific isobaric tags. Proteomics 6: 4321-4334.

Hyman SE (2005). Addiction: a disease of learning and memory. Am J Psychiatry 162: 1414-1422.

Jacobs EH, Spijker S, Verhoog CW, Kamprath K, de Vries TJ, Smit $\mathrm{AB}$ et al (2002). Active heroin administration induces specific genomic responses in the nucleus accumbens shell. Faseb J 16: 1961-1963.

Kalivas PW (2009). The glutamate homeostasis hypothesis of addiction. Nat Rev Neurosci 10: 561-572.

Kalivas PW, Volkow ND (2005). The neural basis of addiction: a pathology of motivation and choice. Am J Psychiatry 162: 1403-1413.

Kalivas PW, Volkow N, Seamans J (2005). Unmanageable motivation in addiction: a pathology in prefrontal-accumbens glutamate transmission. Neuron 45: 647-650.

Kawaguchi Y, Kondo S (2002). Parvalbumin, somatostatin and cholecystokinin as chemical markers for specific GABAergic interneuron types in the rat frontal cortex. J Neurocytol 31: 277-287.

Kelley AE (2004). Memory and addiction: shared neural circuitry and molecular mechanisms. Neuron 44: 161-179.

Koya E, Spijker S, Voorn P, Binnekade R, Schmidt ED, Schoffelmeer AN et al (2006). Enhanced cortical and accumbal molecular reactivity associated with conditioned heroin, but not sucrose-seeking behaviour. J Neurochem 98: 905-915.

LaLumiere RT, Kalivas PW (2008). Glutamate release in the nucleus accumbens core is necessary for heroin seeking. J Neurosci 28: 3170-3177.

Li KW, Miller S, Klychnikov O, Loos M, Stahl-Zeng J, Spijker S et al (2007). Quantitative proteomics and protein network analysis of hippocampal synapses of CaMKIIalpha mutant mice. J Proteome Res 6: 3127-3133.

Malemud CJ (2006). Matrix metalloproteinases (MMPs) in health and disease: an overview. Front Biosci 11: 1696-1701.

McFarland K, Kalivas PW (2001). The circuitry mediating cocaineinduced reinstatement of drug-seeking behavior. J Neurosci 21: 8655-8663.

McFarland K, Lapish CC, Kalivas PW (2003). Prefrontal glutamate release into the core of the nucleus accumbens mediates cocaineinduced reinstatement of drug-seeking behavior. J Neurosci 23: 3531-3537.

Meighan SE, Meighan PC, Choudhury P, Davis CJ, Olson ML, Zornes PA et al (2006). Effects of extracellular matrix-degrading proteases matrix metalloproteinases 3 and 9 on spatial learning and synaptic plasticity. J Neurochem 96: 1227-1241.
Miller CA, Marshall JF (2004). Altered prelimbic cortex output during cue-elicited drug seeking. J Neurosci 24: 6889-6897.

Murakami T, Ohtsuka A (2003). Perisynaptic barrier of proteoglycans in the mature brain and spinal cord. Arch Histol Cytol 66: 195-207.

Nestler EJ (2002). Common molecular and cellular substrates of addiction and memory. Neurobiol Learn Mem 78: 637-647.

O’Brien CP, Ehrman RN, Ternes JW (1986). Classical Conditioning in Human Opioid Dependence. Academic Press: Orlando.

Odake S, Morita Y, Morikawa T, Yoshida N, Hori H, Nagai Y (1994). Inhibition of matrix metalloproteinases by peptidyl hydroxamic acids. Biochem Biophys Res Commun 199: 1442-1446.

Peters J, Kalivas PW, Quirk GJ (2009). Extinction circuits for fear and addiction overlap in prefrontal cortex. Learn Mem 16: 279-288.

Peters J, LaLumiere RT, Kalivas PW (2008a). Infralimbic prefrontal cortex is responsible for inhibiting cocaine seeking in extinguished rats. J Neurosci 28: 6046-6053.

Peters J, Vallone J, Laurendi K, Kalivas PW (2008b). Opposing roles for the ventral prefrontal cortex and the basolateral amygdala on the spontaneous recovery of cocaine-seeking in rats. Psychopharmacology Berl 197: 319-326.

Pizzorusso T, Medini P, Berardi N, Chierzi S, Fawcett JW, Maffei L (2002). Reactivation of ocular dominance plasticity in the adult visual cortex. Science 298: 1248-1251.

Pizzorusso T, Medini P, Landi S, Baldini S, Berardi N, Maffei L (2006). Structural and functional recovery from early monocular deprivation in adult rats. Proc Natl Acad Sci USA 103: 8517-8522.

$\mathrm{Pu}$ L, Bao GB, Xu NJ, Ma L, Pei G (2002). Hippocampal long-term potentiation is reduced by chronic opiate treatment and can be restored by re-exposure to opiates. J Neurosci 22: 1914-1921.

Robinson TE, Berridge KC (1993). The neural basis of drug craving: an incentive-sensitization theory of addiction. Brain Res Brain Res Rev 18: 247-291.

Robinson TE, Gorny G, Savage VR, Kolb B (2002). Widespread but regionally specific effects of experimenter- versus self-administered morphine on dendritic spines in the nucleus accumbens, hippocampus, and neocortex of adult rats. Synapse 46: 271-279.

Robinson TE, Kolb B (1999). Morphine alters the structure of neurons in the nucleus accumbens and neocortex of rats. Synapse 33: 160-162.

Rogers JL, Ghee S, See RE (2008). The neural circuitry underlying reinstatement of heroin-seeking behavior in an animal model of relapse. Neuroscience 151: 579-588.

Saal D, Dong Y, Bonci A, Malenka RC (2003). Drugs of abuse and stress trigger a common synaptic adaptation in dopamine neurons. Neuron 37: 577-582.

Saghatelyan AK, Dityatev A, Schmidt S, Schuster T, Bartsch U, Schachner M (2001). Reduced perisomatic inhibition, increased excitatory transmission, and impaired long-term potentiation in mice deficient for the extracellular matrix glycoprotein tenascinR. Mol Cell Neurosci 17: 226-240.

Schmidt ED, Voorn P, Binnekade R, Schoffelmeer AN, De Vries TJ (2005). Differential involvement of the prelimbic cortex and striatum in conditioned heroin and sucrose seeking following long-term extinction. Eur J Neurosci 22: 2347-2356.

Seidenbecher CI, Richter K, Rauch U, Fassler R, Garner CC, Gundelfinger ED (1995). Brevican, a chondroitin sulfate proteoglycan of rat brain, occurs as secreted and cell surface glycosylphosphatidylinositol-anchored isoforms. I Biol Chem 270: $27206-27212$.

Steketee JD (2005). Cortical mechanisms of cocaine sensitization. Crit Rev Neurobiol 17: 69-86.

Tjon GH, De Vries TJ, Ronken E, Hogenboom F, Wardeh G, Mulder AH et al (1994). Repeated and chronic morphine administration causes differential long-lasting changes in dopaminergic neurotransmission in rat striatum without changing its delta- and kappa-opioid receptor regulation. Eur J Pharmacol 252: 205-212. 
Tjon Tien Ril HK, De Vries TJ, Wardeh G, Hogenboom F, Mulder AH, Schoffelmeer AN (1993). Long-lasting reciprocal changes in striatal dopamine and acetylcholine release upon morphine withdrawal. Eur J Pharmacol 235: 321-322.

Van den Oever MC, Goriounova NA, Li KW, Van der Schors RC, Binnekade R, Schoffelmeer AN et al (2008). Prefrontal cortex AMPA receptor plasticity is crucial for cue-induced relapse to heroin-seeking. Nat Neurosci 11: 1053-1058.

Van den Oever MC, Spijker S, Li KW, Jimenez CR, Koya E, Van der Schors RC et al (2006). A proteomics approach to identify long-term molecular changes in rat medial prefrontal cortex resulting from sucrose self-administration.J Proteome Res 5: $147-154$.

Van den Oever MC, Spijker S, Smit AB, De Vries TJ (2009). Prefrontal cortex plasticity mechanisms in drug seeking and relapse. Neurosci Biobehav Rev, doi:10.1016/j.neurobiorev. 2009.11.016 (in press).
Vanderschuren LJ, De Vries TJ, Wardeh G, Hogenboom FA, Schoffelmeer AN (2001). A single exposure to morphine induces long-lasting behavioural and neurochemical sensitization in rats. Eur J Neurosci 14: 1533-1538.

Wegner F, Hartig W, Bringmann A, Grosche J, Wohlfarth K, Zuschratter $\mathrm{W}$ et al (2003). Diffuse perineuronal nets and modified pyramidal cells immunoreactive for glutamate and the GABA(A) receptor alphal subunit form a unique entity in rat cerebral cortex. Exp Neurol 184: 705-714.

Wikler A (1973). Dynamics of drug dependence. Implications of a conditioning theory for research and treatment. Arch Gen Psychiatry 28: 611-616.

Wright JW, Harding JW (2009). Contributions of matrix metalloproteinases to neural plasticity, habituation, associative learning and drug addiction. Neural Plast 2009: 579382.

Yamaguchi Y (2000). Lecticans: organizers of the brain extracellular matrix. Cell Mol Life Sci 57: 276-289.

Supplementary Information accompanies the paper on the Neuropsychopharmacology website (http://www.nature.com/npp) 